\title{
Commentary: Hurry up while you are operating...or, better, plan carefully before you start
}

\author{
Marek A. Deja, MD, PhD
}

\author{
From the Department of Cardiac Surgery, School of Medicine in Katowice, Medical University of Silesia, \\ Katowice, Poland. \\ Disclosures: Author has nothing to disclose with regard to commercial support. \\ Received for publication Feb 9, 2019; accepted for publication Feb 11, 2019; available ahead of print April 5, \\ 2019. \\ Address for reprints: Marek A. Deja, MD, PhD, Department of Cardiac Surgery, Medical University of Silesia, ul \\ Ziołowa 47, 40-635 Katowice, Poland (E-mail: mdeja@sum.edu.pl). \\ J Thorac Cardiovasc Surg 2020;159:179 \\ $0022-5223 / \$ 36.00$ \\ Copyright (c) 2019 by The American Association for Thoracic Surgery \\ https://doi.org/10.1016/j.jtcvs.2019.02.051
}

Acute renal failure (ARF) developing after cardiac surgery has long been perceived as a dreadful complication that carries a very high mortality, exceeding $60 \%$ in some reports. ${ }^{1}$ Even if the patients survive, they have a prolonged postoperative course, often resulting in a permanent need for hemodialysis. The reported incidence of postoperative ARF varies widely, from $2 \%$ to $30 \%$, depending on the definition used. ${ }^{2}$ ARF is often a part of a rather complicated postoperative course, and factors such as low cardiac output or postoperative bleeding with the need for numerous transfusions play a role in its development and subsequent mortality. The obvious predisposing factor is preoperative renal dysfunction, as signified by a low estimated glomerular filtration rate (eGFR). In addition, a prolonged perfusion time has long been recognized as associated with higher risk of development of postoperative renal failure. ${ }^{2}$

From this point of view, the article of Axtell and colleagues $^{3}$ published in this issue of the Journal brings little new. More than $20 \%$ of patients with a preoperative eGFR less than $30 \mathrm{~mL} / \mathrm{min} / 1.73 \mathrm{~m}^{2}$ developed postoperative ARF, in contrast to fewer than $1 \%$ of those with a preoperative eGFR greater than $60 \mathrm{~mL} / \mathrm{min} / 1.73 \mathrm{~m}^{2}$. The inhospital mortality among patients with postoperative ARF requiring renal replacement therapy was $42 \%$. The postoperative transfusion increased the risk of development of ARF 12 times. The duration of cardiopulmonary bypass (CPB) was positively associated with development of $\mathrm{ARF}$, with an odds ratio of 1.06 for every 10-minute increment. In fact, the perfusion time was on average 32 minutes longer in patients with postoperative ARF, which is very close to the earlier published estimate of 25 minutes from the meta-analysis of Kumar and associates. ${ }^{2}$ Still, as they say, a picture is worth a thousand words. And it is just the central image that I will remember from the article of Axtell

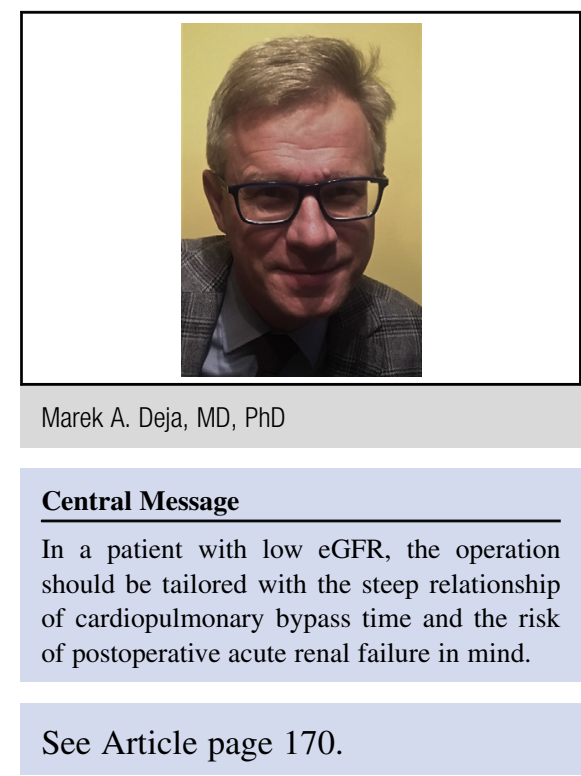

and colleagues. ${ }^{3}$ Although the odds ratio of 1.06 per $10 \mathrm{mi}-$ nutes of CPB might be difficult to imagine, and the goal of shortening the CPB by 30 minutes difficult to accomplish, the central image provided by Axtell and colleagues ${ }^{3}$ is easy to remember and speaks to the imagination. It clearly demonstrates how the risk of development of postoperative ARF rises with the increasing CPB time. And the rise seems particularly steep and early with a lower preoperative eGFR. Thus, rather than hurrying while operating on a patient with predisposing risk factors, we should think carefully on what we are actually planning to achieve while discussing the treatment's risks and benefits with the patient. And perhaps we should tailor the operation with the picture provided by Astell and colleagues ${ }^{3}$ in mind.

\section{References}

1. Chertow GM, Levy EM, Hammermeister KE, Grover F, Daley J. Independent association between acute renal failure and mortality following cardiac surgery. Am J Med. 1998;104:343-8.

2. Kumar AB, Suneja M, Bayman EO, Weide GD, Tarasi M. Association between postoperative acute kidney injury and duration of cardiopulmonary bypass: a meta-analysis. J Cardiothorac Vasc Anesth. 2012;26:64-9.

3. Axtell AL, Fiedler AG, Melnitchouk S, D'Alessandro DA, Villavicencio MA Jassar AS, et al. Correlation of cardiopulmonary bypass duration with acute renal failure after cardiac surgery. J Thorac Cardiovasc Surg. 2020;159:170-8.e2. 